\title{
Characterizations of polybenzoxazine modified with isomeric biphenyltetracarboxylic dianhydrides
}

\author{
S. Rimdusit ${ }^{1 *}$, B. Ramsiri ${ }^{1}$, C. Jubsilp ${ }^{2}$, I. Dueramae ${ }^{1}$ \\ ${ }^{1}$ Polymer Engineering Laboratory, Department of Chemical Engineering, Faculty of Engineering, Chulalongkorn \\ University, 10330 Bangkok, Thailand \\ ${ }^{2}$ Department of Chemical Engineering, Faculty of Engineering, Srinakharinwirot University, 26120 Nakhonnayok, \\ Thailand
}

Received 25 February 2012; accepted in revised form 22 April 2012

\begin{abstract}
A series of polymeric alloying films were prepared from bisphenol A/aniline-based bifunctional benzoxazine resin (BA-a) with three isomeric biphenyltetracarboxylic dianhydrides, i.e., 2,3',3,4'-biphenyltetra carboxylic dianhydride (a-BPDA), 2,2',3,3'-biphenyltetracarboxylic dianhydride (i-BPDA), and 3,3',4,4'-biphenyltetracarboxylic dianhydride (s-BPDA) through fully thermal curing. Chemical structure, thermomechanical property and thermal stability of bisphenol A/aniline type polybenzoxazine (PBA-a) copolymers were evaluated. Their chemical structures analyzed via Fourier transform infrared spectroscopy reveal ester carbonyl linkage formation between hydroxyl group of the PBA-a and anhydride group in the isomeric dianhydride. Glass transition temperatures $\left(T_{\mathrm{g}} \mathrm{s}\right)$ of the dianhydride-modified PBA-a increased with PBA-a $<<$ i-BPDA $<$ a-BPDA $<$ s-BPDA. Degradation temperatures $\left(T_{\mathrm{d}}\right)$ of the PBA-a copolymers recorded to be in the range of $365-402^{\circ} \mathrm{C}$ were significantly higher than that of the neat PBA-a i.e. $334^{\circ} \mathrm{C}$. Finally, char yield of the PBA-a copolymers was found to be about $54-57 \%$ which is about twofold increase from that of the parent PBA-a.
\end{abstract}

Keywords: polymer blends and alloys, polybenzoxazine, isomeric dianhydride, thermal properties, mechanical properties

\section{Introduction}

Polybenzoxazine, synthesized by the ring-opening polymerization reaction of cyclic benzoxazine resin only by thermal treatment without the need of catalyst and without producing any harmful by-products during the polymerization process, is recognized as an interesting new class of phenolic resin [1-5]. Moreover, polybenzoxazine provides some characteristics such as excellent dimension stability, high heat resistance, flame retardance and low moisture absorption as well as good dielectric properties in which cannot be found in traditional phenolic resins $[6,7]$. Alloying of polybenzoxazine with various other resins or polymers has been reported to economically provide a novel class of resin systems with superior performance $[1,4,8-15]$. How- ever, the major shortcoming of polybenzoxazine is its relatively high rigidity. Therefore, various efforts have been done to toughen polybenzoxazine such as by easily blending with more flexible monomers or polymers e.g. flexible epoxy resins $[9,12]$, urethane elastomers $[8,13]$, polyimides $[14,15]$ or dianhydrides $[16,17]$.

In recent reports, thermal and thermo-oxidative stabilities of polybenzoxazines have been substantially improved by alloying techniques [8, 15-18]. Alloying between benzoxazine resin and epoxy resin is considered to be a potentially effective measure to enhance thermal, mechanical properties, and flammability as well as processability of the polymers. Rimdusit et al. [12] investigated effects of epoxy resin on various arylamine-based benzoxazine resins,

\footnotetext{
${ }^{*}$ Corresponding author, e-mail: sarawut.r@chula.ac.th
} (C) BME-PT 
i.e. aniline (BA-a), m-toluidine (BA-mt), and 3,5xylidine (BA-35x) on processability, thermal, and mechanical properties of the polybenzoxazine copolymers. The authors reported that processing windows of the polybenzoxazine copolymers were found to be widened with epoxy resin content. Glass transition temperature $\left(T_{\mathrm{g}}\right)$ of the polybenzoxazine copolymers, i.e., PBA-a/epoxy resin and PBA-mt/epoxy resin, exhibited a synergistic behavior with the maximum $T_{\mathrm{g}}$ value, i.e. 183 and $215^{\circ} \mathrm{C}$, respectively, at the polybenzoxazine blended with epoxy content of $20 \mathrm{wt} \%$. Moreover, flexural strength and elongation at break of the polybenzoxazine alloys increased with increasing amount of the epoxy resin. Spontón et al. [19] developed a mixture of bis(m-aminophenyl)methylphosphine oxidebased benzoxazine (Bz-BAMPO) and glycidylether (DGEBA). The authors reported that the BzBAMPO: DGEBA at 2:1 mole ratio showed degradation temperature $\left(T_{\mathrm{d}}\right)$ at $5 \%$ weight loss of about $347^{\circ} \mathrm{C}$ compared to $333^{\circ} \mathrm{C}$ of Bz-BAMPO. Moreover, thermomechanical properties of bisphenol A and aniline-based polybenzoxazine (PBA-a) modified with highly flexible urethane elastomer (PU) [13] were reported. The obtained $T_{\mathrm{g}}$ of the PBA-a: PU copolymers was in a range of 177 to $245^{\circ} \mathrm{C}$ which was substantially greater than those of the parent polymers, i.e. $T_{\mathrm{g}}=166^{\circ} \mathrm{C}$ for PBA-a, and $T_{\mathrm{g}}=-70^{\circ} \mathrm{C}$ for PU. Coefficient of thermal expansion of the copolymers showed a minimum value at PBA-a:PU (90:10) mass ratio. In addition, flexural strength of the alloys also exhibited a synergistic characteristic at the PBA-a:PU mass ratio of 90:10 with an ultimate value of $142 \mathrm{MPa}$. Takeichi et al. [15] disclosed a performance improvement of bisphenol A and aniline type polybenzoxazine (PBA-a) by blending with polyimide (PI). The authors reported that $T_{\mathrm{g}}$ values, degradation temperature and char yield of the copolymers were enhanced as the PI component increased. $T_{\mathrm{g}}$ of the PBA-a:PI copolymers was in a range of $186-205^{\circ} \mathrm{C}$ which was greater than that of the neat polybenzoxazine.

In more recent reports, organic acid dianhydrides have been shown to easily copolymerize with benzoxazine resin leading to substantially higher crosslink density of the copolymer network, thus greatly enhancing thermal stability of the polybenzoxazine $[15,16]$. Jubsilp et al. [16] reported property enhancement of a novel bisphenol A and anilinebased polybenzoxazine (PBA-a) modified with 3,3',4,4'-benzophenonetetracarboxylic dianhydride (BTDA). Fourier-transform infrared spectroscopy (FTIR) reveals ester linkage formation between hydroxyl group of the PBA-a and anhydride group of the BTDA. The PBA-a:BTDA copolymer films showed single $T_{\mathrm{g}}$ with the value as high as $263^{\circ} \mathrm{C}$ at $\mathrm{BA}-\mathrm{a}: \mathrm{BTDA}=1.5: 1$ mole ratio. The value is remarkably higher than that of the unmodified PBA-a. In addition, the resulting PBA-a:BTDA copolymers display relatively high thermal stability with $T_{\mathrm{d}}$ at $5 \%$ weight loss up to $364^{\circ} \mathrm{C}$ and substantial enhancement in char yield at $800^{\circ} \mathrm{C}$ with a value up to $61 \%$ vs. that of $38 \%$ of the PBA-a.

In this work, a series of aromatic biphenyltetracarboxylic dianhydride isomers including a-BPDA, i-BPDA, and s-BPDA are investigated for their ability to form copolymer with bisphenol A-based benzoxazine resin (BA-a). The three isomers are originally synthesized to provide polyimides with improved solubility [20-22]. Curing behaviors, dynamic mechanical properties and thermal stability of the obtained polybenzoxazine copolymers are also reported.

\section{Experimental}

\subsection{Materials}

Materials used in this study are bisphenol A/aniline-based bifunctional benzoxazine resin (BA-a), dianhydrides, 1-methyl-2-pyrrolidone (NMP) as solvent. Benzoxazine resin based on bisphenol A, paraformaldehyde and aniline was synthesized according to the patented solventless technology [7]. Bisphenol A (polycarbonate grade) was provided by Thai Polycarbonate Co., Ltd., TPCC, (Rayong, Thailand). Paraformaldehyde (AR grade) and aniline (AR grade) were purchased from Merck Co., Ltd. (Darmstadt, Germany) and Panreac Quimica SA (Barcelona, Spain), respectively. Biphenyltetracarboxylic dianhydride isomers which are 2,3',3,4'biphenyltetracarboxylic dianhydride (a-BPDA), 2,2',3,3'-biphenyltetracarboxylic dianhydride (i-BPDA), and 3,3',4,4'-biphenyltetracarboxylic dianhydride (s-BPDA) are obtained from Japan Aerospace Exploration Agency, JAXA, (Prof. R. Yokota) (Ibaraki, Japan) and Akron Polymer Systems, Inc. (Ohio, United States). 1-methyl-2-pyrroli- 
done (NMP) solvent was purchased from Fluka Chemical Co. (Bushs, Switzerland). All chemicals were used as-received.

BA-a resin was blended with various types of biphenyltetracarboxylic dianhydride isomers (DA) at BA-a:DA $=4: 1,3: 1,2: 1,1.5: 1$, and 1:1 mole ratios. The mixtures were dissolved in NMP and stirred at $80^{\circ} \mathrm{C}$ until a clear homogeneous mixture was obtained. The solution was cast on Teflon sheet and dried at room temperature for $24 \mathrm{~h}$. Additional drying was carried out at $80^{\circ} \mathrm{C}$ for $24 \mathrm{~h}$ in a vacuum oven followed by thermal curing at $170^{\circ} \mathrm{C}$ for $1 \mathrm{~h}$, at $190,210,230^{\circ} \mathrm{C}$ for $2 \mathrm{~h}$ each and $240^{\circ} \mathrm{C}$ for $1 \mathrm{~h}$ to guarantee complete curing of the mixtures.

\subsection{Characterization methods}

Glass transition temperatures $\left(T_{\mathrm{g}}\right)$ of all specimens were determined using a differential scanning calorimeter (DSC) model 2910 from TA Instruments (New Castle, DE, United States). The thermogram was obtained using a heating rate of $10^{\circ} \mathrm{C} / \mathrm{min}$ from 30 to $300^{\circ} \mathrm{C}$ under nitrogen purging with a constant flow $50 \mathrm{~mL} / \mathrm{min}$. The specimen with a mass of 8-10 mg was sealed in an aluminum pan

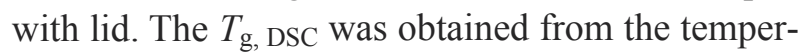
ature at half extrapolated tangents of the step transition midpoint.

Fourier transform infrared spectra of fully cured specimens were acquired at room temperature using a Spectrum GX FT-IR spectometer with an ATR accessory from PerkinElmer, Inc. (Waltham, Massachusette, United States). In the case of a BA-a and a pure biphenyltetracarboxylic isomers, a small amount of biphenyltetracarboxylic isomer powder was cast as thin film on a potassium bromide $(\mathrm{KBr})$ window. All spectra were taken with 64 scans at a resolution of $4 \mathrm{~cm}^{-1}$ and in a spectral range of 4000 $400 \mathrm{~cm}^{-1}$.

A dynamic mechanical analyzer (DMA) model DMA242 from Netzsch, Inc. (Bavaria, Germany) was used to investigate viscoelastic properties of all specimens. The dimension of specimens has a width of $7.0 \mathrm{~mm}$, a long $10 \mathrm{~mm}$, and a $0.1 \mathrm{~mm}$ thick. The test was performed in a tension mode at a frequency of $1 \mathrm{~Hz}$ with a strain value of $0.1 \%$ and at a heating rate of $2^{\circ} \mathrm{C} / \mathrm{min}$ from 30 to $400^{\circ} \mathrm{C}$ under nitrogen atmosphere with a constant flow $80 \mathrm{~mL} / \mathrm{min}$. The storage modulus $\left(E^{\prime}\right)$, loss modulus $\left(E^{\prime \prime}\right)$, and loss tangent or damping curve $(\tan \delta)$ were then obtained.
The $T_{\mathrm{g} \text {, DMA }}$ was taken as the maximum point on the loss modulus curve in the DMA thermograms.

Degradation temperature $\left(T_{\mathrm{d}}\right)$ at $5 \%$ weight loss and char yield at $800^{\circ} \mathrm{C}$ of all specimens were acquired using a Diamond TG/DTA from PerkinElmer, Inc. (Waltham, Massachusetts, United States). The testing temperature program was ramped at a heating rate of $20^{\circ} \mathrm{C} / \mathrm{min}$ from 30 to $1000^{\circ} \mathrm{C}$ under nitrogen purging with a constant flow of $50 \mathrm{~mL} / \mathrm{min}$. The sample mass used was approximately $15 \mathrm{mg}$. $T_{\mathrm{d}} \mathrm{S}$ and char yields of the specimens were reported at their $5 \%$ weight loss and at $800^{\circ} \mathrm{C}$, respectively.

\section{Results and discussion}

\subsection{Optimal composition of}

\section{$\mathrm{BA}-\mathrm{a}$ :dianhydride isomer mixtures}

DSC thermograms of the fully cured PBA-a copolymers of BA-a:s-BPDA at various mole ratios ranging from $4: 1,3: 1,2: 1,1.5: 1$ and $1: 1$ are depicted in Figure 1. From this figure, we can see that the glass transition temperature $\left(T_{\mathrm{g}, \mathrm{DSC}}\right)$ determined from a mid-point in initial slope change of DSC thermograms of the PBA-a copolymers increases with increasing amount of s-BPDA content until BA-a: $\mathrm{s}-\mathrm{BPDA}=1.5: 1$ mole ratio and then the $T_{\mathrm{g}}$, DSC value of the copolymer at 1:1 mole ratio tends to decrease. In other words, the ultimate value of $T_{\mathrm{g}}$, DSC of the copolymer was obtained at the BA-a:s-BPDA composition of 1.5:1 mole. All of the fully cured PBAa:s-BPDA copolymers showed only single $T_{\mathrm{g}}$, DSC ranging from 170 to $257^{\circ} \mathrm{C}$ suggesting a single phase

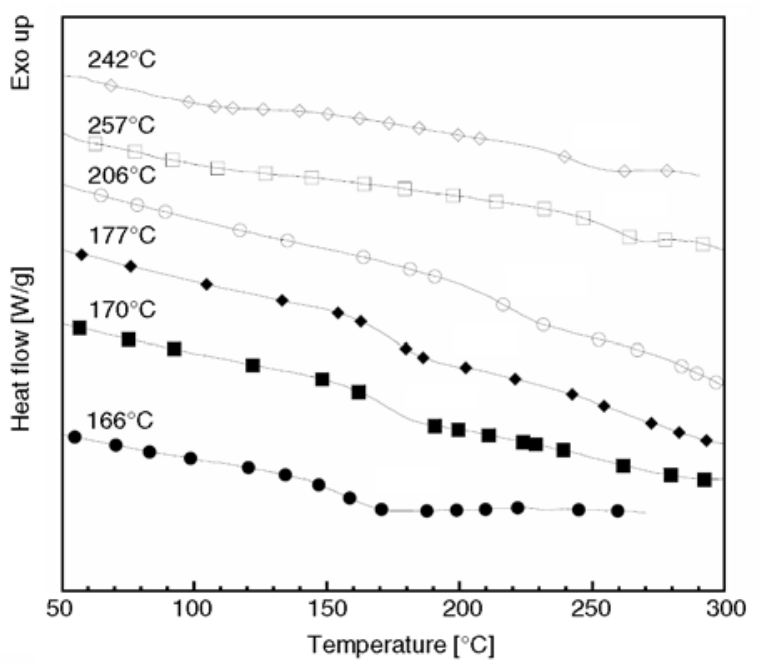

Figure 1. DSC thermograms of PBA-a:s-BPDA copolymer films at various mole ratios: $(\bullet)$ PBA-a, ( $\bullet$ BA-a: s-BPDA $=4: 1,(\diamond)$ BA-a:s-BPDA = 3:1, ( ( ) BA-a: $\mathrm{s}-\mathrm{BPDA}=2: 1,(\square) \mathrm{BA}-\mathrm{a}: \mathrm{s}-\mathrm{BPDA}=1.5: 1$, and $(\diamond)$ BA-a:s-BPDA = 1:1 
material in these PBA-a-dianhydride copolymers. Those values are substantially greater than the $T_{\mathrm{g} \text {, DSC }}$ of the neat PBA-a i.e. $166^{\circ} \mathrm{C}$. From the $T_{\mathrm{g} \text {, DSC }}$ results, the optimal network formation reaction of the PBA-a copolymers clearly required greater moles of benzoxazine monomers than those of the s-BPDA or did not follow the stoichiometric ratio of the two monomers. This is because an ability of the benzoxazine monomers to undergo self-polymerizability upon heating besides their ability to react with the dianhydrides. As a consequence, the consumption of the benzoxazine monomers tended to be greater than that of the dianhydrides in order to form a perfect network which may be related to the phenoxy-phenolic rearrangement that occurs during the formation for PBA-a [23]. This result is also in good agreement with the reaction of BA-a with BTDA [16]. In addition, DSC thermograms of the fully cured BA-a:a-BPDA and BA-a:i-BPDA copolymers at various dianhydride contents (not shown here) also provided similar trend on the $T_{\mathrm{g}}$

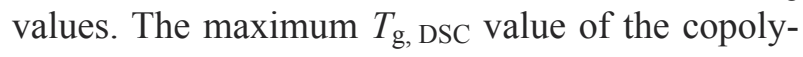
mers prepared from BA-a:a-BPDA $=1.5: 1$ mole and BA-a:i-BPDA $=1.5: 1$ mole indicated about 245 and $237^{\circ} \mathrm{C}$, respectively. The results show that each isomeric BPDA significantly affected the glass transition temperature of the copolymers as previously observed in polyimides based on isomeric BPDA [24].

\subsection{Network formation by thermal cure of PBA-a:dianhydride isomer copolymers}

Chemical structures of BA-a, PBA-a, isomeric dianhydride modifiers and their network formation reactions between the PBA-a and those isomeric dianhydride modifiers were studied using Fourier transform infrared spectroscopy (FT-IR) technique. The FT-IR absorption bands of the BA-a resin are previously reported in details $[1,15,18]$. In Figure 2, the important characteristics of infrared absorptions of BA-a resin were obviously observed at 947 and $1497 \mathrm{~cm}^{-1}$ attributed to the tri-substituted benzene ring and at $1232 \mathrm{~cm}^{-1}$ assigned to the asymmetric stretching of $\mathrm{C}-\mathrm{O}-\mathrm{C}$ group of oxazine ring. On the other hand, the biphenyltetracarboxylic dianhydride isomers, i.e., a-BPDA, i-BPDA, and s-BPDA, were identified by a distinctive carbonyl band region. From Figure 2, the spectrum of biphenyltetracarboxylic dianhydride isomer, e.g. a-BPDA, provided

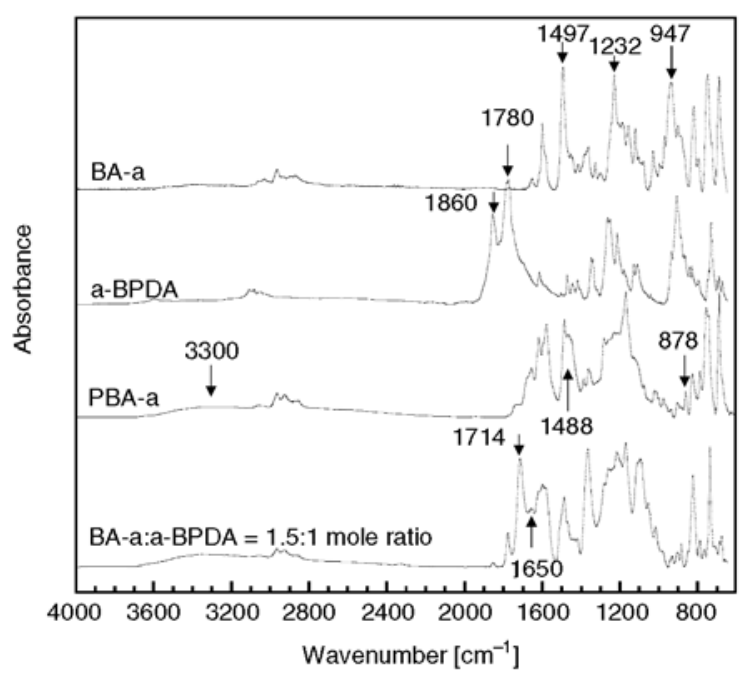

Figure 2. FTIR spectra of isomeric biphenyltetracarboxylic dianhydrides-modified PBA-a films of BA-a: a-BPDA = 1.5:1 mole

the characteristic absorption peaks with component in the $1780-1740 \mathrm{~cm}^{-1}$ region assigned to symmetric and $1860-1800 \mathrm{~cm}^{-1}$ region assigned to asymmetric starching of strong anhydride carbonyl groups $[16,25]$. After thermal curing, an infinite three dimensional network was formed from benzoxazine ring opening by the breakage of $\mathrm{C}-\mathrm{O}$ bond and then the benzoxazine molecule transformed from a ring structure to a network structure $[6,26]$. During this curing process via ring opening reaction of the BA-a resin upon thermal treatment, the tri-substituted benzene ring around $1497 \mathrm{~cm}^{-1}$ which is the backbone of benzoxazine ring, became tetra-substituted benzene ring centered at 1488 and $878 \mathrm{~cm}^{-1}$ which led to the formation of a phenolic hydroxyl groupbased polybenzoxazine structure. The phenolic hydroxyl group is also confirmed by the appearance of new absorption peak about $3300 \mathrm{~cm}^{-1}$.

The chemical transformations of BA-a:a-BPDA at 1.5:1 mole ratio upon thermal curing were investigated and the resulting spectra are shown in Figure 2. The new absorption bands of PBA-a:a-BPDA copolymer were observed. The phenomenon was ascribed to the appearance of carbonyl stretching bands of ester linkages. From the PBA-a:biphenyltetracarboxylic dianhydride isomer spectrum in Figure 2, we can see that the anhydride carbonyl stretching bands of biphenyltetracarboxylic dianhydride at 1860 and $1780 \mathrm{~cm}^{-1}$ completely disappeared. It was suggested that the reaction between the phenolic hydroxyl group of the PBA-a and the 
anhydride group of the biphenyl tetracarboxylic dianhydride isomer could occur to form ester carbonyl linkage as evidenced by the observed peak in the spectrum at $1730-1700 \mathrm{~cm}^{-1}$ of its $\mathrm{C}=\mathrm{O}$ stretching of ester carbonyl group bonded phenolic hydroxyl group of the PBA-a modified with biphenyltetracarboxylic dianhydride [18]. Furthermore, the carboxylic acid occurred after thermal curing of the PBA-a:dianhydride isomer mixture can also be followed by monitoring a band at $1650-1670 \mathrm{~cm}^{-1}$ due to $\mathrm{C}=\mathrm{O}$ stretching [27]. In addition, carboxylic acid shows characteristic $\mathrm{C}-\mathrm{O}-\mathrm{H}$ in-plane bending band at $1440-1395 \mathrm{~cm}^{-1}, \mathrm{C}-\mathrm{O}$ stretching band at 1320 $1210 \mathrm{~cm}^{-1}$, and $\mathrm{C}-\mathrm{O}-\mathrm{H}$ out-of-plane bending band at $960-900 \mathrm{~cm}^{-1}$, respectively $[25,28]$. Furthermore, the FTIR results for the i-BTDA and s-BTDAmodified PBA-a (not shown here) are relatively similar to a-BTDA-modified PBA-a.

As a consequence, the proposed reaction model of these mixtures was shown in Figure 3 which was similar to the cure reaction between anhydride group and hydroxyl group of the ring-opened epoxide group to form the ester carbonyl linkage [29-31] and a diglycidyl ether of bisphenol A-based epoxide resin (DGEBA) with dodecyl succinic anhydride (DDSA) [32] as well as reaction between BTDA

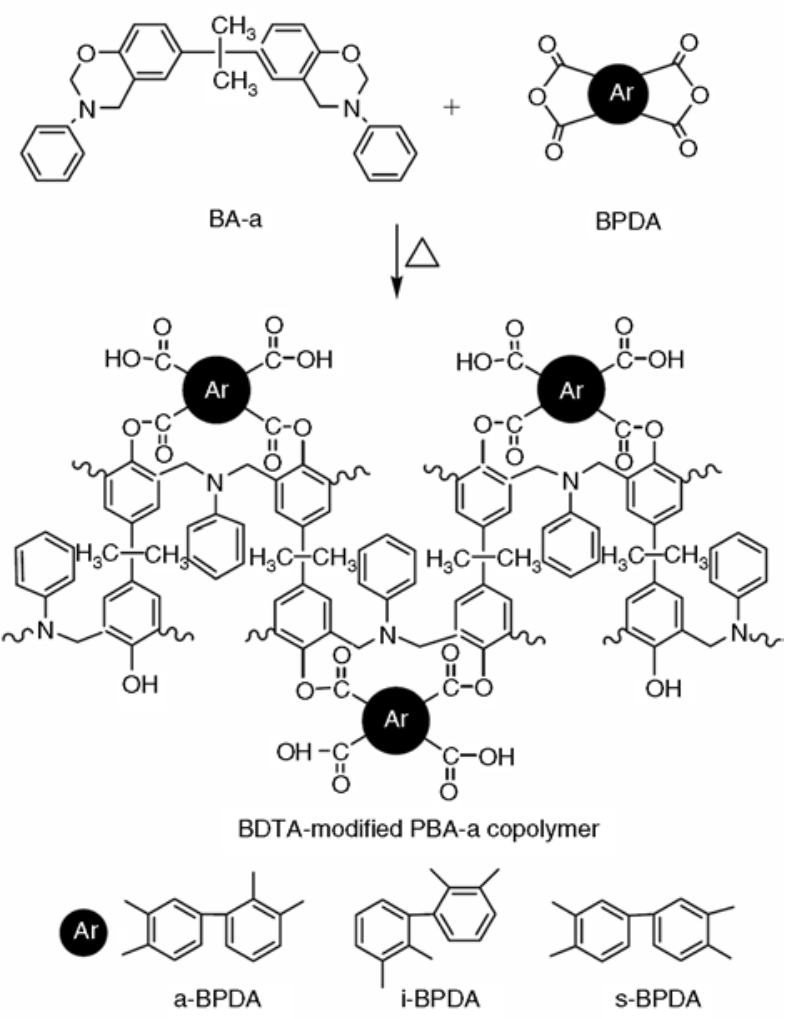

Figure 3. Model compound of isomeric BPDA-modified polybenzoxazine copolymers dianhydride and hydroxyl group of 2-hydroxyethyl acrylate (HEA) [33].

\subsection{Thermomechanical properties of PBA-a:dianhydride isomer copolymers}

The mechanical properties of the PBA-a modified with isomeric biphenyltetracarboxylic dianhydrides, i.e. BA-a:a-BPDA, BA-a:i-BPDA, and BA-a:sBPDA at 1.5:1 mole ratio were measured as a function of temperature. In this study dynamic tensile property was applied as dynamic mechanical analysis (DMA). The DMA thermograms were displayed in Figure 4, 5 and 6, respectively. Generally, the storage modulus of the materials demonstrates the deformation resistances of material when external force were applied sinusoidally. The storage moduli at room temperature $\left(25^{\circ} \mathrm{C}\right)$ of PBA-a:a-BPDA, PBA-a:i-BPDA, and PBA-a: s-BPDA copolymers exhibited the values of $2.91,2.89$ and $3.42 \mathrm{GPa}$, respectively, which were higher than that of the neat PBA-a of $2.57 \mathrm{GPa}$ as shown in Figure 4. This is due to higher crosslink density and greater aromatic content of the PBA-a copolymers with a greater amount of the isomeric biphenyltetracarboxylic dianhydride.

The effects of isomeric biphenyltetracarboxylic dianhydride on the crosslink density, $\rho_{\mathrm{x}}$, of their polymer alloy network can be calculated from a value of the equilibrium storage shear modulus in the rubbery region, $G_{\mathrm{e}}^{\prime}$, which equals to $E_{\mathrm{e}}^{\prime} / 3$ as follow in Equation (1) derived from the statistical theory of rubber elasticity by Nielsen [34]:

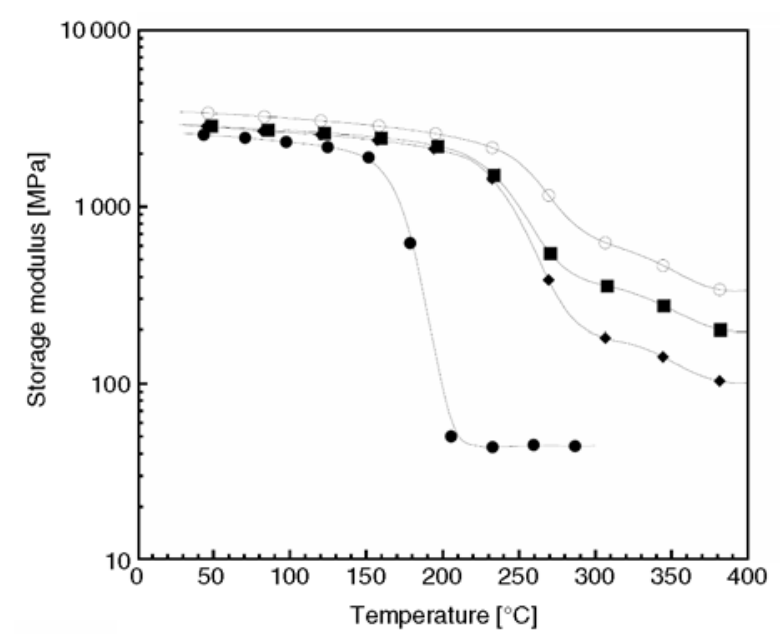

Figure 4. Storage modulus of isomeric biphenyltetracarboxylic dianhydrides-modified PBA-a films of BA-a:BPDA = 1.5:1 mole: $(\bullet)$ PBA-a, (ø) PBA-a: a-BPDA, ( $\bullet$ PBA-a:i-BPDA, ( ) PBA-a:s-BPDA 
$\log \left(E_{\mathrm{e}}^{\prime} / 3\right)=7.0+293\left(\rho_{\mathrm{x}}\right)$

where $E_{\mathrm{e}}^{\prime}$ is an equilibrium storage modulus in rubbery plateau $\left[\right.$ dyne $/ \mathrm{cm}^{2}$ ] and $\rho_{\mathrm{x}}$ is crosslink density $\left[\mathrm{mol} / \mathrm{cm}^{3}\right]$ which is the mole number of network chains per unit volume of the polymers.

As expected, crosslink density values of the PBA-a and its copolymers i.e. PBA-a:a-BPDA, PBA-a: i-BPDA, and PBA-a:s-BPDA, calculated from Equation (1) are 3981, 7157, 6353 and $7664 \mathrm{~mol} / \mathrm{m}^{3}$, respectively. It is evident that the crosslink density of the neat PBA-a was greatly enhanced by an addition of isomeric biphenyltetracarboxylic dianhydrides, corresponding to an enhancement in their storage modulus values discussed previously. Moreover, we can see that the storage modulus at room temperature of the isomeric BPDA-modified PBA-a copolymer films increases with i-BPDA $<$ a-BPDA $<$ s-BPDA as similarly reported in polyimide film derived from isomeric $\mathrm{BPDA} / p, p^{\prime}$-ODA and isomeric BPDA/1,4,4-APB [35]. This behavior results from the greater interaction of the macromolecules and denser packing of s-BPDA than those of a-BPDA and i-BPDA. In case of i-BPDA based polyimides, the polyimides tend to form internal cyclization which may be lead to obtain lower interaction of the macromolecules and rather low molecular weights than s-BPDA based polyimides [36].

Figure 5 displays glass transition temperature, the maximum point on the loss modulus curve ( $T_{\mathrm{g}}$, DMA $)$, related to molecular motion at structural level determimed from of the PBA-a:a-BPDA, PBA-a:i-BPDA, and PBA-a:s-BPDA copolymer films. From the figure, the neat PBA-a and its copolymers showed only single $T_{\mathrm{g} \text {, DMA }}$ as reported in DSC thermogram in Figure 1. This result suggested that all kinds of PBA-a:isomeric biphenyltetracarboxylic dianhydride copolymer films were homogeneous and no phase separation occurred in these copolymers. From Figure 5, the $T_{\mathrm{g} \text {, DMA }}$ value of the neat PBA-a was determined to be about $178^{\circ} \mathrm{C}$ and those of the PBA-a modified with isomeric biphenyltetracarboxylic dianhydrides films were found to be in the range of $239-266^{\circ} \mathrm{C}$. The $T_{\mathrm{g}}$, DMA value of the neat PBA-a was clearly enhanced by blending with the a-BPDA or i-BPDA or s-BPDA dianhydrides. The obtained high $T_{\mathrm{g}}$, DMA value of PBA-a:isomeric biphenyltetracarboxylic dianhydride copolymers can be attributed to the improved crosslink structure

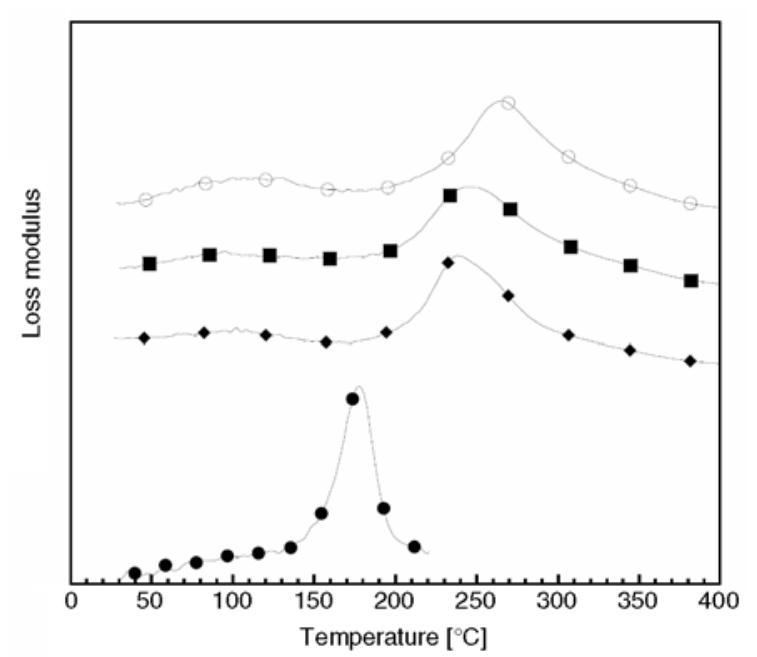

Figure 5. Loss modulus of isomeric biphenyltetracarboxylic dianhydrides-modified PBA-a films of BA-a:BPDA = 1.5:1 mole: $(\bullet)$ PBA-a, $(\bullet)$ PBA-a: a-BPDA, ( $)$ PBA-a:i-BPDA, ( ) PBA-a:s-BPDA

via ester carbonyl linkage between phenolic hydroxyl group of PBA-a and anhydride group of isomeric biphenyltetracarboxylic dianhydride as seen in FT-IR spectra and their high aromatic content from the presence of the dianhydrides in the copolymers network as well as hydrogen bonding between ester carbonyl group $(\mathrm{C}=\mathrm{O})$ or $\mathrm{OH}$ groups in a carboxylic acid and phenolic hydroxyl group $(-\mathrm{OH})$ of the PBA-a. Moreover, the $T_{\mathrm{g}}$ values of PBA-a copolymers measured by DMA displayed descending order on basis of both molecular packing and chain conformation such as semirigid s-BPDA and bent chain a-BPDA structures of isomeric biphenyltetracarboxylic dianhydrides [37, 38]. In our experiments, the order of $T_{\mathrm{g}}$ 's PBA-a: s-BPDA $\left(266^{\circ} \mathrm{C}\right)>$ PBA-a:a-BPDA $\left(247^{\circ} \mathrm{C}\right)>$ PBA-a: i-BPDA $\left(239^{\circ} \mathrm{C}\right)$ was observed as similarly investigated in [23]. This observation implied that the $T_{\mathrm{g}}$ values were also dependent on stiff/linear chain of these isomeric biphenyltetracarboxylic dianhydride moieties that a decrease in the chain linearity as follow s-BPDA $>$ a-BPDA $>$ i-BPDA caused an increase of energy to motivate motions in PBA-a:s-BPDA copolymer as compared with that of PBA-a:a-BPDA and PBA-a:iBPDA copolymers and thus results in higher $T_{\mathrm{g}}$ for the PBA-a:s-BPDA copolymer as compared to latter copolymers.

The loss tangent $(\tan \delta)$ of the neat PBA-a and their copolymers with various types of isomeric biphenyltetracarboxylic dianhydrides was illustrated in Figure 6. The peak height of the $\tan \delta$ of the PBA-a: 


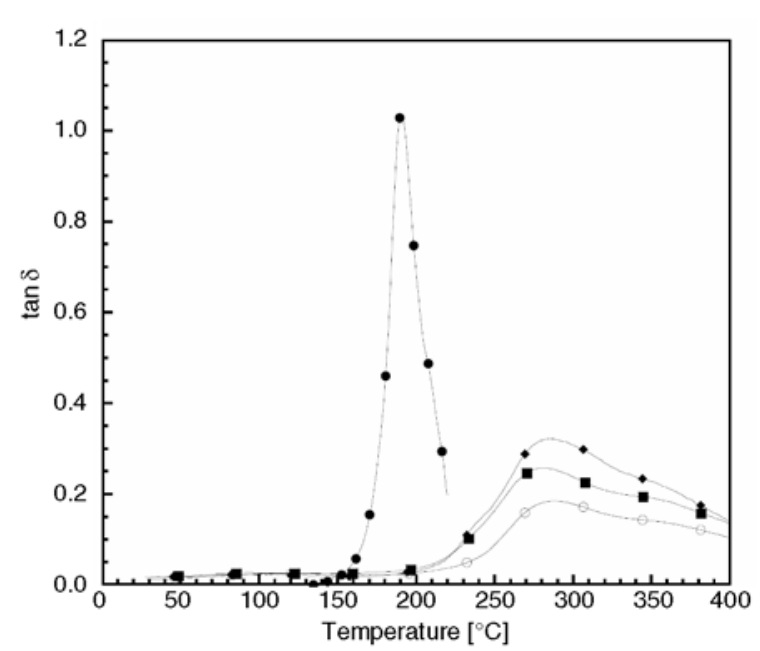

Figure 6. Loss tangent of isomeric biphenyltetracarboxylic dianhydrides-modified PBA-a films of BA-a: BPDA $=$ 1.5:1 mole: $(\bullet)$ PBA-a, (ø) PBA-a: a-BPDA, ( $)$ PBA-a:i-BPDA, ( ) PBA-a:s-BPDA

a-BPDA, PBA-a:i-BPDA, and PBA-a:s-BPDA tended to decrease while the peak position of their PBA-a copolymers shifted to a higher temperature. The results indicated that the increase in the crosslink density with decreasing the chain's segmental mobility in the PBA-a modified with biphenyltetracarboxylic dianhydride isomers. This characteristic of the copolymers conformed to increasing of $T_{\mathrm{g}}$ 's copolymer as follow s-BPDA> a-BPDA $>$ i-BPDA. Furthermore, the width-at-halfheight of $\tan \delta$ curves was broader in their PBA-a

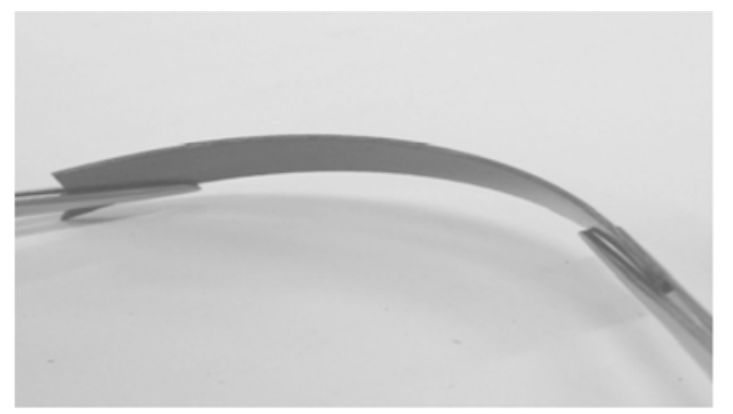

a)

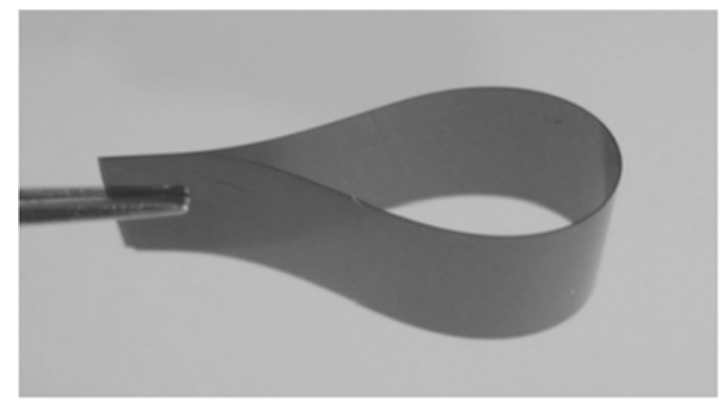

c) copolymers, which confirmed the more heterogeneous network in the resulting copolymers due to a hybrid polymer network formation. Moreover, the obtained transparent copolymer films and the single $\tan \delta$ peak observed in each copolymer suggested no macroscopic phase separation in their PBA-a copolymer films.

\subsection{Visual appearance of PBA-a:dianhydride isomer copolymers}

Because of the ester carbonyl linkage, structurally flexible functional group, formed after thermal curing stages, the enhancement of the PBA-a:dianhydride isomer copolymer bending was expected. A transparent brown neat PBA-a film and red brown PBA-a blended with isomeric biphenyltetracarboxylic dianhydrides at the neat BA-a equal to 1.5 mole and dianhydride isomer equal to 1 mole which showed the highest $T_{\mathrm{g} \text {, DMA }}$ value of the PBA-a copolymers were obtained. The visual appearances of the cured PBA-a copolymer specimens are presented in Figure 7. We can see that the PBA-a specimen of about $100 \mu \mathrm{m}$ thick is rather brittle, and it can not be bent further than as shown in Figure 7a due to the internal hydrogen bonding among hydroxyl and amino groups of the PBA-a. Whereas the homogeneous specimens of all the PBA-a copolymers of the same thickness as illustrated in Figures $7 b-7 d$ showed a remarkable improvement in their tough-

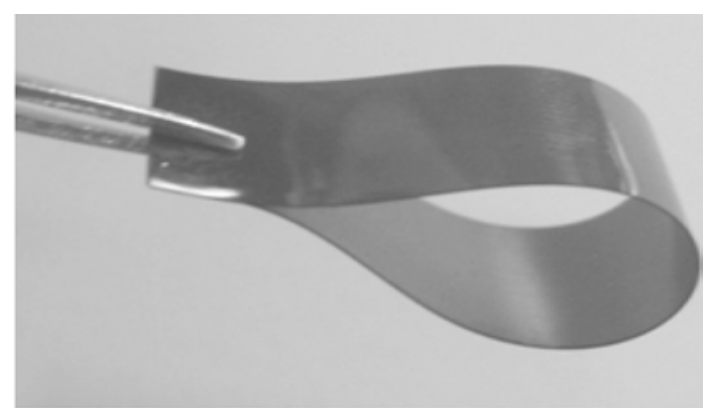

b)

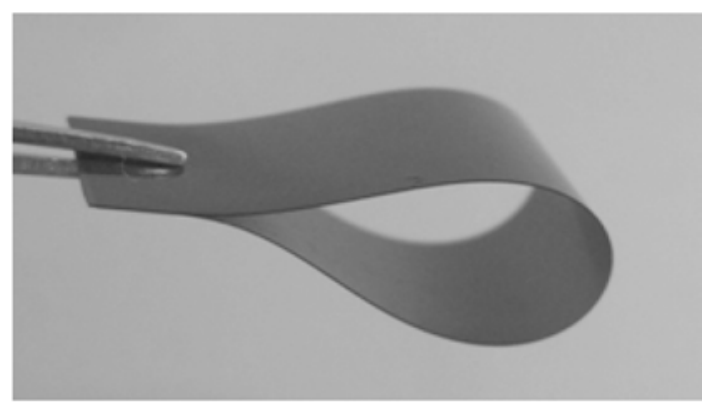

d)

Figure 7. Visual appearances of isomeric biphenyltetracarboxylic dianhydrides-modified PBA-a films of BA-a:BPDA = 1.5:1 mole: (a) PBA-a, (b) PBA-a:a-BPDA, (c) PBA-a:i-BPDA, (d) PBA-a:s-BPDA 
ness. The toughness enhancement of the PBA-a copolymer specimens, actually, due to ester carbonyl linkages $(\mathrm{C}=\mathrm{O})$ formed in the PBA-a copolymer network. Moreover, the formation of the esters might result in the breaking of the internal hydrogen bonding of the PBA-a. The new hydrogen-bonding tends to be random; therefore, the total polymer network structure could be more flexible. In addition, the great toughness of the PBA-a copolymers in Figures $7 b-7 d$ is similar to that of the commercial polyimide films such as UPILEX ${ }^{\circledR} \mathrm{S}$ film presented by Ube Industries, Ltd. and Kapton ${ }^{\circledR} \mathrm{H}$ films [39].

\subsection{Thermal stability of PBA-a:dianhydride isomer copolymers}

Figure 8 depicted the TGA thermogram results of three kinds of representative isomeric biphenyltetracarboxylic dianhydride-modified PBA-a, i.e., PBA-a:a-BPDA, PBA-a:i-BPDA, and PBA-a: s-BPDA copolymer films consisted of BA-a equal to 1.5 mole and dianhydride isomer equal to 1 mole. The degradation temperature $\left(T_{\mathrm{d}}\right)$, expressed as the $5 \%$ weight loss under nitrogen atmosphere in TGA of the neat PBA-a, was determined to be $334^{\circ} \mathrm{C}$. The $T_{\mathrm{d}}$ values at $5 \%$ weight loss of the all sort of PBA-a:isomeric biphenyltetracarboxylic dianhydrides copolymer films were higher than that of the neat PBA-a films, i.e., $379^{\circ} \mathrm{C}$ for PBA-a:a-BPDA, $365^{\circ} \mathrm{C}$ for PBA-a:i-BPDA, and $402^{\circ} \mathrm{C}$ for PBA-a: s-BPDA. This is due to the effect of the ester carbonyl linkage formation in the PBA-a copolymer network as the $T_{\mathrm{d}}$ of polyester reported $\sim 353-550^{\circ} \mathrm{C}$

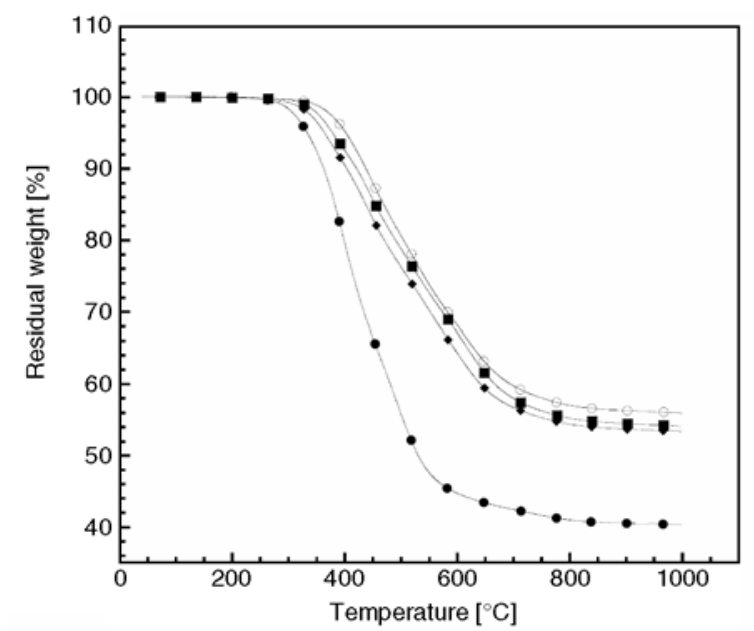

Figure 8. TGA thermograms of isomeric biphenyltetracarboxylic dianhydrides-modified PBA-a films of BA-a:BPDA = 1.5:1 mole: $(\bullet)$ PBA-a, (๘) PBA-a: a-BPDA, ( ) PBA-a:i-BPDA, ( ) PBA-a:s-BPDA
$[40,41]$ which had higher thermal stability than that of the neat PBA-a. In addition, the improved crosslink density of the PBA-a with an addition of the isomeric biphenyltetracarboxylic dianhydrides via esterification reaction between the hydroxyl group of the polybenzoxazine and the anhydride group of the isomeric dianhydrides as mentioned previously as well as additional hydrogen bonding between $-\mathrm{OH}$ group and $\mathrm{C}=\mathrm{O}$ group in the copolymers. Moreover, we can see that $T_{\mathrm{d}}$ at $5 \%$ weight loss in TGA falls in the same order as $T_{\mathrm{g}}$ : i.e., $T_{\mathrm{d}}$ at $5 \%$ weight loss of the PBA-a copolymers with respect to the structure of isomeric biphenyltetracarboxylic dianhydride component increases in the order of i-BPDA $<$ a-BPDA $<$ s-BPDA which shows the similar trend in polyimides based on isomeric biphenyltetracarboxylic dianhydrides [42]. Interestingly, $T_{\mathrm{g}}$-thermal energy absorption relationship shows that the molecular chain with greater mobility or lower $T_{\mathrm{g}}$ may absorb more thermal energy and less thermal stability than a chain with less mobility.

Additionally, the amount of carbonized residue (char yield) at $800^{\circ} \mathrm{C}$ under nitrogen for the PBA-a and all kind of the PBA-a:isomeric biphenyltetracarboxylic dianhydride copolymer films also showed in Figure 8. Their PBA-a:isomeric biphenyltetracarboxylic dianhydride copolymer films were 54,55 and $60 \%$ for i-BPDA, a-BPDA, and s-BPDAmodified PBA-a, respectively, which was much great than that of the neat PBA-a (i.e. $38 \%$ at $800^{\circ} \mathrm{C}$ ). The high char yield of these PBA-a copolymers due to their higher aromatic content in the molecular structure and enhanced crosslink density through inter hydrogen bonding in the copolymers of the resulting PBA-a copolymers as previously reported in [16].

\section{Conclusions}

High temperature bisphenol-A-aniline type polybenzoxazine (PBA-a) copolymer films were prepared from mixtures of BA-a resin and a-BPDA, $i-$ BPDA, or s-BPDA isomeric biphenyltetracarboxylic dianhydrides. The obtained network structures were due to reaction between the hydroxyl group of polybenzoxazine and the anhydride group of isomeric biphenyltetracarboxylic dianhydrides. The $T_{\mathrm{g}}$ value, crosslink density, and $T_{\mathrm{d}}$ value of PBA-a was enhanced by blending with the isomeric biphenylte- 
tracarboxylic dianhydrides. Moreover, $T_{\mathrm{g}}$ and $T_{\mathrm{d}}$ values of polybenzoxazine copolymers with respect to the structure of isomeric aromatic carboxylic dianhydride were as follow: PBA-a:s-BPDA $>$ PBA-a: a-BPDA $>$ PBA-a:i-BPDA. The char yield of their copolymer films at $800^{\circ} \mathrm{C}$ under nitrogen is much higher than that of the neat polybenzoxazine. Therefore, the polybenzoxazine modified with the isomeric biphenyltetracarboxylic dianhydrides should be considered as good potential candidates for hightemperature resistant materials with outstanding mechanical integrity at high temperatures.

\section{Acknowledgements}

This research is supported by the Rachadaphiseksomphot Endowment Fund Part of the "Strengthen CU's Researcher's Project," and the Higher Education Research Promotion and National Research University Project of Thailand, Office of the Higher Education Commission (AM1076A). Additional fund was also provided by Research Grants of Faculty of Engineering and Research Grants of Graduate School, Srinakharinwirot University 2011 (C. Jubsilp). The authors would like to acknowledge Prof. Rikio Yokota of JAXA, Japan for the research fellowship of S.R. Bisphenol A is kindly provided by Thai Polycarbonate Co., Ltd. (TPCC).

\section{References}

[1] Ishida H.: Handbook of benzoxazine resins. Elsevier, New York (2011).

[2] Ghosh N. N., Kiskan B., Yagci Y.: Polybenzoxazines New high performance thermosetting resins: Synthesis and properties. Progress in Polymer Science, 32, 1344 1391 (2007).

DOI: 10.1016/j.progpolymsci.2007.07.002

[3] Santhosh Kumar K. S., Reghunadhan Nair C. P.: Polybenzoxazines: Chemistry and properties. Rapra, Shawbury (2010).

[4] Reghunadhan Nair C. P.: Advances in addition-cure phenolic resins. Progress in Polymer Science, 29, 401498 (2004).

DOI: $10.1016 /$ j.progpolymsci.2004.01.004

[5] Cao G. P., Chen W. J., Wei J. J., Li W. T., Liu X. B.: Synthesis and characterization of a novel bisphthalonitrile containing benzoxazine. Express Polymer Letters, 8, 512-518 (2007).

DOI: $10.3144 /$ expresspolymlett.2007.73

[6] Ishida H., Low H. Y.: A study on the volumetric expansion of benzoxazine-based phenolic resin. Macromolecules, 30, 1099-1106 (1997).

DOI: $10.1021 / \mathrm{ma960539a}$

[7] Ishida H.: Process for preparation of benzoxazine compounds in solventless systems. U.S. Patent 5543516, USA (1996).
[8] Rimdusit S., Pirstpindvong S., Tanthapanichakoon W., Damrongsakkul S.: Toughening of polybenzoxazine by alloying with urethane prepolymer and flexible epoxy: A comparative study. Polymer Engineering and Science, 45, 288-296 (2005).

DOI: $10.1002 /$ pen. 20273

[9] Jubsilp C., Takeichi T., Hiziroglu S., Rimdusit S.: Effect of resin compositions on microwave processing and thermophysical properties of benzoxazine-epoxyphenolic ternary systems filled with silicon carbide (SiC) whisker. Polymer Engineering and Science, 49, 1022-1029 (2009).

DOI: $10.1002 /$ pen. 21358

[10] Grishchuk S., Mbhele Z., Schmitt S., Karger-Kocsis J.: Structure, thermal and fracture mechanical properties of benzoxazine-modified amine-cured DGEBA epoxy resins. Express Polymer Letters, 3, 273-282 (2011). DOI: $10.3144 /$ expresspolymlett.2011.27

[11] Kimura H., Ohtsuka K., Matsumoto A.: Curing reaction of bisphenol-A based benzoxazine with cyanate ester resin and the properties of the cured thermosetting resin. Express Polymer Letters, 5, 1113-1122 (2011).

DOI: $10.3144 /$ expresspolymlett.2011.108

[12] Rimdusit S., Kunopast P., Dueramae I.: Thermomechanical properties of arylamine-based benzoxazine resins alloyed with epoxy resin. Polymer Engineering and Science, 51, 1797-1807 (2011).

DOI: 10.1002/pen.21969

[13] Rimdutsit S., Bangsen W., Kasemsiri P.: Chemorheology and thermomechanical characteristics of benzoxazine-urethane copolymers. Journal of Applied Polymer Science, 121, 3669-3678 (2011).

DOI: $10.1002 / a p p .34170$

[14] Tiptipakorn S., Damrongsakkul S., Ando S., Hemvichain K., Rimdusit S.: Thermal degradation behaviors of polybenzoxazine and silicon-containing polyimide blends. Polymer Degradation and Stability, 92, 12651278 (2007).

DOI: $10.1016 /$ j.polymdegradstab.2007.03.021

[15] Takeichi T., Guo Y., Rimdusit S.: Performance improvement of polybenzoxazine by alloying with polyimide: Effect of preparation method on the properties. Polymer, 46, 4909-4916 (2005).

DOI: $10.1016 /$ j.polymer.2005.03.096

[16] Jubsilp C., Takeichi T., Rimdusit S.: Property enhancement of polybenzoxazine modified with dianhydride. Polymer Degradation and Stability, 96, 1047-1053 (2011).

DOI: $10.1016 /$ j.polymdegradstab.2011.03.021

[17] Rimdusit S., Jubsilp C.: Polymer from modification of polybenzoxazine with anhydride. Thailand Patent 0701003695, Thailand (2007).

[18] Rajput A. B., Ghosh N. N.: Preparation and characterization of novel polybenzoxazine-polyester resin blends. International Journal of Polymeric Materials, 60, 27-39 (2010).

DOI: $10.1080 / 00914037.2010 .504153$ 
[19] Spontón M., Ronda J. C., Galià M., Cádiz V.: Studies on thermal and flame retardant behaviour of mixtures of bis( $m$-aminophenyl)methylphosphine oxide based benzoxazine and glycidylether or benzoxazine of bisphenol A. Polymer Degradation and Stability, 93, 2158-2165 (2008).

DOI: $10.1016 /$ j.polymdegradstab.2008.08.004

[20] Zhou H., Chen C., Kanbara R., Sasaki T., Yokota R.: Synthesis and properties of copolyimides derived from isometric biphenyltetracarboxylic dianhydrides (aBPDA and i-BPDA) and oxydiphthalic dianhydride (ODPA) with 4,4'-oxydianiline (4,4'-ODA). High Performance Polymer, 17, 213-224 (2005).

DOI: $10.1177 / 0954008305044856$

[21] Tong Y., Huang W., Luo J., Ding M.: Synthesis and properties of aromatic polyimides derived from 2,2',3,3'-biphenyltetracarboxylic dianhydride. Journal of Polymer Science Part A: Polymer Chemistry, 37, 1425-1433 (1999).

DOI: $\underline{10.1002 /(\text { SICI)1099-0518(19990515)37:10<1425 }}$ $\because$ AID-POLA4>3.0.CO;2-G

[22] Hergenrother P. M., Watson K. A., Smith Jr J. G., Connell J. W., Yokota R.: Polyimides from 2,3,3',4'-biphenyltetracarboxylic dianhydride and aromatic diamines. Polymer, 43, 5077-5093 (2002).

DOI: $10.1016 / \mathrm{S} 0032-3861(02) 00362-2$

[23] Liu C., Shen D., Sebastián R. M., Marquet J., Schönfeld R.: Mechanistic studies on ring-opening polymerization of benzoxazines: A mechanistically based catalyst design. Macromolecules, 44, 4616-4622 (2011). DOI: $10.1021 / \mathrm{ma} 2007893$

[24] Gerber M. K., Pratt J. R., St Clair T. L.: Materials, chemistry, and characterization. in 'Polyimide' (eds.: Feger C., Khojasteh M. M., MacGrath J. M.) Elsevier, Amsterdam, 487-496 (1989).

[25] Stuart B. H.: Infrared spectroscopy: Fundamentals and applications. Wiley, Chichester (2004).

[26] Dunkers J., Zarate E. A., Ishida H.: Crystal structure and hydrogen-bonding characteristics of $N, N$-bis(3,5dimethyl-2-hydroxybenzyl)methylamine, A benzoxazine dimer. The Journal of Physical Chemistry, 100, 13514-13520 (1996).

DOI: 10.1021/jp961293e

[27] Settle F. A.: Handbook of instrumental techniques for analytical chemistry. Prentice Hall, New Jersey (1997).

[28] Colthup N. B., Daly L. H., Wiberley S. E.: Introduction to infrared and raman spectroscopy. Academic Press, London (1990).

[29] Trappe V., Burchard W., Steinmann B.: Anhydridecured epoxies via chain reaction. 1 . The phenyl glycidyl ether/phthalic acid anhydride system. Macromolecules, 24, 4738-4744 (1991).

DOI: $10.1021 / \mathrm{ma} 00017 \mathrm{a} 002$

[30] Jain R., Choudhary V., Narula A. K.: Curing and thermal behavior of DGEBA in presence of dianhydrides and aromatic diamine. Journal of Applied Polymer Science, 105, 3804-3808 (2007).

DOI: $10.1002 /$ app. 26620
[31] Rocks J., Rintoul L., Vohwinkel F., George G.: The kinetics and mechanism of cure of an amino-glycidyl epoxy resin by a co-anhydride as studied by FT-Raman spectroscopy. Polymer, 45, 6799-6711 (2004).

DOI: $10.1016 /$ j.polymer.2004.07.066

[32] Ghaemy M., Riahy M. H.: Kinetics of anhydride and polyamide curing of bisphenol A-based diglycidyl ether using DSC. European Polymer Journal, 32, $1207-$ 1212 (1996).

DOI: $10.1016 / \mathrm{S} 0014-3057(96) 00066-3$

[33] Chiang W-Y., Chan S-C.: Preparation and properties of UV-autocurable BTDA-based epoxy-multiacrylate resins. Effects of the degree of polymerization and the epoxy type. Journal of Applied Polymer Science, 43, 1827-1836 (1991).

DOI: 10.1002/app.1991.070431006

[34] Nielsen L. E.: Cross-linking-effect on physical properties of polymers. Journal of Macromolecular Science Part C: Polymer Reviews, 3, 69-103 (1969).

DOI: $10.1080 / 15583726908545897$

[35] Fryd M.: Structure-Tg relationship in polyimides. in 'Polyimides: Synthesis, characterizations and properties' (ed.: Mittal K. L.) Plenum Press, New York, Vol 1, 377-383 (1984).

[36] Ding M.: Isomeric polyimides. Progress in Polymer Science, 32, 623-668 (2007).

DOI: $10.1016 /$ j.progpolymsci.2007.01.007

[37] Hasegawa M., Sensui N., Shindo Y., Yokota R.: Structure and properties of novel asymmetric biphenyl type polyimides. Homo- and copolymers and blends. Macromolecules, 32, 387-396 (1999).

DOI: $10.1021 / \mathrm{ma} 9808629$

[38] Li F., Ge J. J., Honigfort P. S., Fang S., Chen J-C., Harris F. W., Cheng S. Z. D.: Dianhydride architectural effects on the relaxation behaviors and thermal and optical properties of organo-soluble aromatic polyimide films. Polymer, 40, 4987-5002 (1999).

DOI: $10.1016 / \mathrm{S} 0032-3861(98) 00721-6$

[39] Hergenrother P. M.: High performance polymers and composites. Wiley, New York (1991).

[40] Evans S. J., Haines P. J., Skinner G. A.: The thermal degradation of polyester resins II. The effects of cure and of fillers on degradation. Thermochimica Acta, 291, 43-49 (1997).

DOI: 10.1016/S0040-6031(96)03102-4

[41] Sato H., Kikuchi T., Koide N., Furuya K.: Thermal degradation and combustion process of liquid crystalline polyesters studied by directly coupled thermal analysis-mass spectrometry. Journal of Analytical and Applied Pyrolysis, 37, 173-183 (1996).

DOI: $10.1016 / 0165-2370(96) 00944-8$

[42] Inoue H., Okamoto H., Hiraoka Y.: Effect of the chemical structure of acid dianhydride in the skeleton on the thermal property and radiation resistance of polyimide. International Journal of Radiation Applications and Instrumentation Part C: Radiation Physics and Chemistry, 29, 283-288 (1987). DOI: $10.1016 / 1359-0197(87) 90033-6$ 